\title{
Direct laser fabricated in situ TiC particulate reinforced Ni30Al20Fe intermetallic matrix composite
}

\author{
$X . Y . X U^{*}$ \\ Surface Modification Laboratory, Institute of Mechanics, Chinese Academy of Sciences, Beijing 100080, \\ People's Republic of China \\ E-mail: xyxu@imech.ac.cn \\ W. J. LIU, M. L. ZHONG, H. Q. SUN \\ Laser Processing Research Center, Department of Mechanical Engineering, Tsinghua University, \\ Beijing 100084, People's Republic of China \\ G. N. CHEN \\ Surface Modification Laboratory, Institute of Mechanics, Chinese Academy of Sciences, Beijing 100080, \\ People's Republic of China
}

$\mathrm{NiAl}$ intermetallics is considered to be a potential high temperature structural material based on a high melting point, low density, high thermal conductivity, excellent oxidation and hot-corrosion resistance at elevated temperatures [1-4], but its high temperature strength is insufficient for the majority of actual applications. The tensile ductility and fracture toughness at ambient temperatures are often also unsatisfactory $[5,6]$. The solid solution strengthening, precipitation strengthening, directional solidification and single crystal technique have been explored to improve its high temperature strength. Although significant progress has been achieved, the ambient tensile ductility and fracture toughness often deteriorate as a result. On the other hand, the ductility and toughness can also be improved by microalloying, macroalloying and plastic secondary phase additions, but this is at the expense of the strength [4-7]. In other words, it is very difficult to compromise its high temperature strength and ambient temperature ductility. This severely restricts its operating temperature and deteriorates its machinability. It is significant to explore novel fabricaturing techniques for $\mathrm{NiAl}$ intermetallic alloy to improve its comprehensive mechanical properties.

Preparing intermetallic matrix composite is an effective method to produce engineering NiAl intermetallic alloy and to improve its high temperature strength and retain ambient temperature ductility simultaneously $[8,9]$. Good ductility can be obtained through adequately alloying the intermetallic matrix while the strength is improved with the reinforcements. The casting, combustion synthesis, powder metallurgy and mechanical alloying are major methods for preparing $\mathrm{NiAl}$ intermetallic matrix composites. Nevertheless, in many cases, the mechanical bonding due to no interfacial reaction, or the brittle reactive products existing at the interface between matrix and reinforcement due to excessive interfacial reaction often result in weak interfacial bonding so that whole properties of the composite might even be worse than the matrix itself.

Based on clear and compatible interface, in situ reinforced composite generally shows better comprehensive mechanical properties than external additive ones. Laser cladding has been introduced to prepare particulate reinforced intermetallic composite coatings, for example, laser clad $\mathrm{TiC} / \mathrm{NiAl}-\mathrm{Ni}_{3}(\mathrm{Al}, \mathrm{Ti}, \mathrm{C})$ wearresistant coating [10]. However, this research was limited to the pure nickel substrate, elemental powder additives, pre-placed powder bed, definite matrix composition and a few reinforcement contents. Moreover, the matrix of the coating was mainly $\mathrm{Ni}_{3} \mathrm{Al}$ phase, no NiAl phase, and the research aimed at the coating preparation, no bulk materials.

In this investigation, laser powder deposition fabricated in situ $\mathrm{TiC}$ particulate reinforced $\mathrm{NiAl}$ intermetallic matrix composite was carried out with $\mathrm{Ni} / \mathrm{Al}, \mathrm{Fe}$ and TiC powders by coaxial powder delivery. In situ $\mathrm{TiC}$ particulate reinforced NiAl intermetallic matrix bulk material was successfully synthesized and fabricated. The microstructure and the interface between the TiC particulate and the matrix were analyzed.

The substrate material in this study was a commercially available mild steel plate. Prior to the laser deposition experiment, the substrate surface was finished, and then washed with acetone for degreasing. Ni/Al cladding powders, with stoichiometric compositions of $\mathrm{NiAl}$ intermetallics, were blended with pure iron fused and crushed powders in the proportion of 18 at. \%, then TiC sintered and crushed powders in the proportion of 20 wt $\%$ were added into Ni/Al plus Fe powder mixtures. The nominal powder sizes were respectively in the range of 22-45 $\mu \mathrm{m}, 53-75 \mu \mathrm{m}$ and 5-45 $\mu \mathrm{m}$. The powder morphologies are showed in Fig. 1a-c.

A $3 \mathrm{~kW}$ continuous wave $\mathrm{CO}_{2}$ laser, attached with a powder feeder and a coaxial powder-feeding nozzle, was used for the laser deposition experiment. Argon was applied as the shield gas to avoid oxidation

*Author to whom all correspondence should be addressed. 

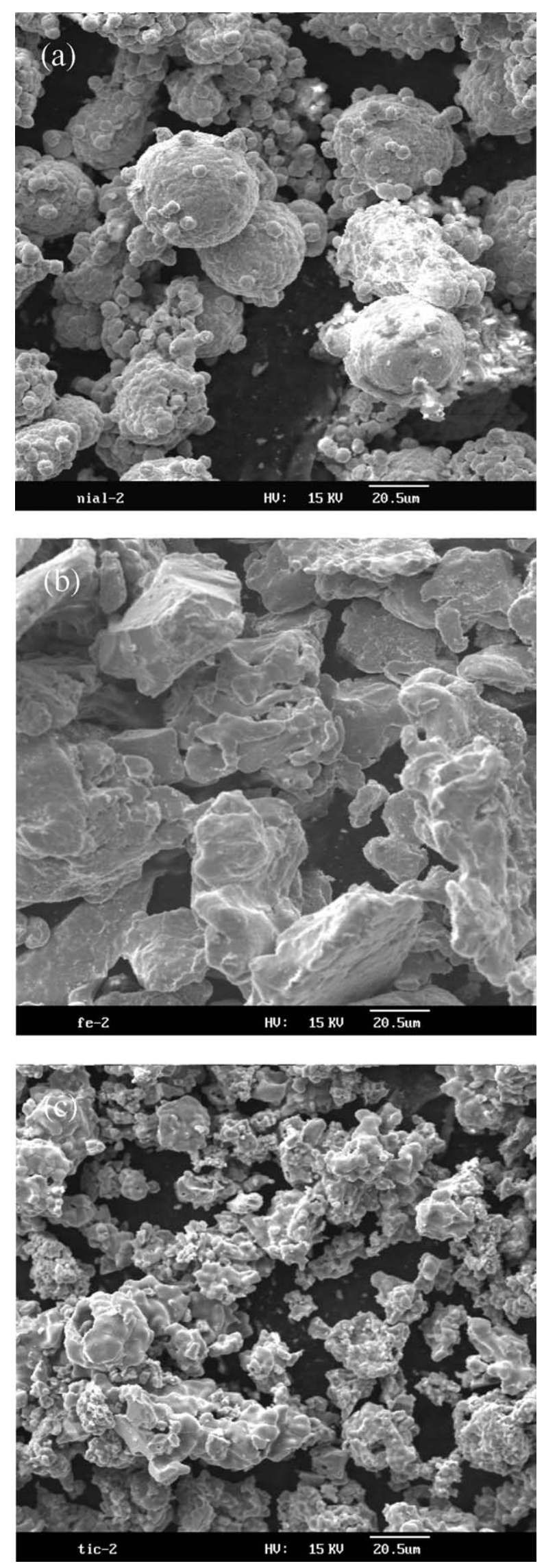

Figure 1 Morphologies of the original powders: (a) Ni/Al powders, (b) Fe powders and (c) TiC powders.

and contamination of the melted powders and pool. Through preliminary processing experiments, the optimized processing parameters were identified to ensure good metallurgical quality: laser power $P=1.5 \mathrm{~kW}$, scanning velocity $V=4 \mathrm{~mm} / \mathrm{s}$, powder feeding rate $Q=4.5 \mathrm{~g} / \mathrm{min}$ and laser beam diameter $D=5 \mathrm{~mm}$. The bulk material was fabricated by track-by-track and layer-by-layer overlapping in the horizontal and vertical directions.

The microstructure of the bulk material was examined by a CSM950 scanning electron microscopy (SEM) and a JSM-6301F high-resolution scanning electron microscopy (HSEM). The material compositions were determined by a Link ISIS energy-dispersive spectrometry (EDS). The phase constituents were identified with a Rigida X-ray diffractometer (XRD). The microhardness was measured by HX-200 Vickers microhardness tester and a load of $100 \mathrm{~g}$.

The surface and cross section morphologies of the laser deposited bulk material were examined with the naked eye and SEM. The results show that the material was fully dense and free of cracks and pores. This should mainly attribute to the optimization of processing parameters. Since slightly lower laser power, slower scanning velocity and larger beam diameter were used, the heating and cooling rates were slowed down and the temperature distribution was more uniform in the deposits. As a result, the thermal stress in the deposited material could be reduced considerably so that cracking was eliminated. Because the melting pool could be retained for a longer time, the gases dissolved could escape fully so that pores could be eliminated and the fully dense bulk material could be obtained.

The XRD profile of the laser deposited bulk material is given in Fig. 2. It is found that the actual position of every diffraction peak is exactly identical to JCPDS standard data of $\beta$-NiAl (B2 structure) and TiC (Cubic structure). Therefore it can preliminarily be considered that the laser deposited bulk material mainly consists of the $\beta$-NiAl intermetallics and TiC phase. Furthermore, it can be found later that the titanium carbides were precipitated in situ.

Fig. 3 is the SEM images of the microstructure of the laser deposited bulk material. Fig. 3a is a full view of the morphology of the microstructure. A quantity of refined and dispersed particles, whose sizes are far smaller than the original TiC additives, homogeneously distributed on the matrix. The chemical compositions of the matrix and precipitated particles are given in Table I. The compositions of the matrix are in the range of $\beta$ phase area in Ni-Al-Fe ternary phase diagram [11]. It can be considered as a Ni30Al20Fe alloy. It must be pointed out that $\mathrm{Al}$ concentration in the bulk material was reduced, compared to the original powders, due to oxidation and evaporation in the process of laser deposition. The dispersed particles mainly include $\mathrm{Ti}$ and $\mathrm{C}$ elements with a near iso-atomic proportion. $\mathrm{A}$ few $\mathrm{Ni}, \mathrm{Al}$ and $\mathrm{Fe}$

TABLE I Chemical compositions of laser deposited bulk material (at.\%)

\begin{tabular}{lrrrrl}
\hline Positions & \multicolumn{1}{l}{$\mathrm{Ni}$} & $\mathrm{Al}$ & $\mathrm{Fe}$ & $\mathrm{Ti}$ & $\mathrm{C}$ \\
\hline The matrix & 49.32 & 29.86 & 19.13 & 1.69 & - \\
The particle & 2.52 & 2.81 & 5.63 & 47.79 & 41.25 \\
The $\gamma$ phase & 45.28 & 7.94 & 46.26 & 0.52 & - \\
\hline
\end{tabular}




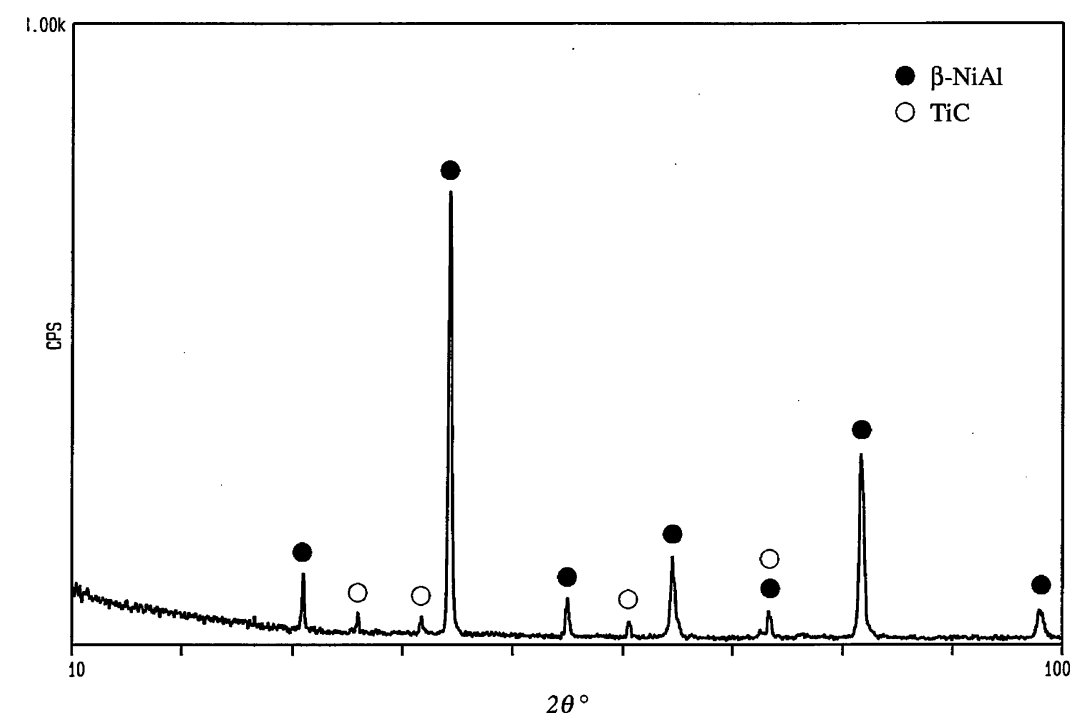

Figure 2 XRD profile of laser deposited bulk material.

particles are also found in the dispersed particles because they are so tiny that compositional information of the adjacent matrix was inevitably collected. According to Table I, in combination with the XRD results in Fig. 2, it is affirmable that the matrix is a $\mathrm{NiAl}$ intermetallic alloy dissolved with $\mathrm{Fe}$ and Ti atoms and the precipitated particles are titanium carbides. For comparison, the microstructure obtained under inappropriate processing conditions, where relatively low laser power density was used, is shown in Fig. 3b. In this case the $\mathrm{TiC}$ particles are apparently coarser than the ones in Fig. 3a and similar to original particles shown in Fig. 1c. This means that the majority of the TiC particles are unmelted. This also proves that the bulk material obtained under the optimum processing variables is in situ $\mathrm{TiC}$ particulate reinforced $\mathrm{NiAl}$ intermetallic matrix composite. The in situ TiC particles may be formed in two steps: first, the TiC powder particles melt down or are dissolved into the liquid melting pool when heated, and then re-precipitated when cooled and solidified. In order to obtain in situ TiC particles, it is critical that original $\mathrm{TiC}$ particles must completely melt or dissolve, and then sufficiently precipitate.

Fig. $3 \mathrm{c}$ is the microstructure of the matrix of the laser deposited bulk material. It is composed of homogeneous equiaxed grains of $5 \mu \mathrm{m}$ or so. A few superfine particles, whose compositions are given in Table I, can be recognized. According to other researches, some $\mathrm{Ni}-\mathrm{Al}-\mathrm{Fe}$ series intermetallic alloys included a few fcc $\gamma$-Fe-Ni phases that usually precipitated from $\beta$-NiAlFe phases and were distributed along crystal boundaries in appearance of lamellar or particle and could serve as the ductile improvement [11]. So they should be Ferich $\gamma$-Fe-Ni phase precipitated from $\beta$ phase, although they were not enough to be identified by XRD analysis. Fig. $3 d$ is a highly-enlarged SEM image giving a clear insight on the in situ $\mathrm{TiC}$ reinforcements and the adjacent matrix. The in situ TiC particles are characterized by their fine size, quasi-quadrangle shape, and cube spatial configuration.
Fig. 4 is the HSEM images of the single unmelted and in situ $\mathrm{TiC}$ particle and their interfaces with the matrix. The unmelted TiC particle shown in Fig. 4a has a size of $20 \mu \mathrm{m}$ or so while the in situ TiC particle shown in Fig. $4 \mathrm{~b}$ is only $1 \mu \mathrm{m}$ in size. This means that the in situ TiC particle is much smaller than the additive TiC particle. The fine and dispersed TiC particles are favorable to the improvement of the whole properties of the $\mathrm{NiAl}$ intermetallic alloy. The interface between the unmelted $\mathrm{TiC}$ particle and the matrix, as shown in Fig. $4 \mathrm{c}$, is discontinuous and exhibits a mechanical bonding feature. It is more readily etched than the matrix and the particle, so that the deeper etching track can be found. Conversely, the interface between the in situ $\mathrm{TiC}$ particle and the matrix is very clear and continuous. The interface structure of the in situ $\mathrm{TiC}$ particle will specifically be further investigated.

The average microhardness of the laser deposited bulk material reached $\mathrm{HV}_{0.1} 595$, which was much higher than HV250-350, the microhardness of Ni-AlFe intermetallic alloys.

Based on the above research results, the following conclusions can be drawn. With the mechanical mixtures of $\mathrm{Ni} / \mathrm{Al}$ cladding powders, $\mathrm{Fe}$ fused and crushed powders and TiC sintered and crushed powders, as well as coaxial powder feeding mode, in situ TiC particulate reinforced Ni30Al20Fe intermetallic matrix composite could be successfully synthesized and prepared by laser powder deposition. Under optimized processing parameters, laser deposited bulk material was fully dense and free of cracks and pores. The microstructure of in situ $\mathrm{TiC}$ particulate reinforced Ni30Al20Fe intermetallic matrix composite consisted of the refined $\beta$-NiAl-Fe intermetallic matrix, homogeneous and dispersive in situ $\mathrm{TiC}$ reinforcements and discontinuous $\gamma$-Fe-Ni phases. The microhardness of the bulk material, $\mathrm{HV}_{0.1} 595$, was much higher than $\mathrm{Ni}-\mathrm{Al}-\mathrm{Fe}$ intermetallic alloys without reinforcements. This could mainly be attributed to in situ particulate reinforcement. 

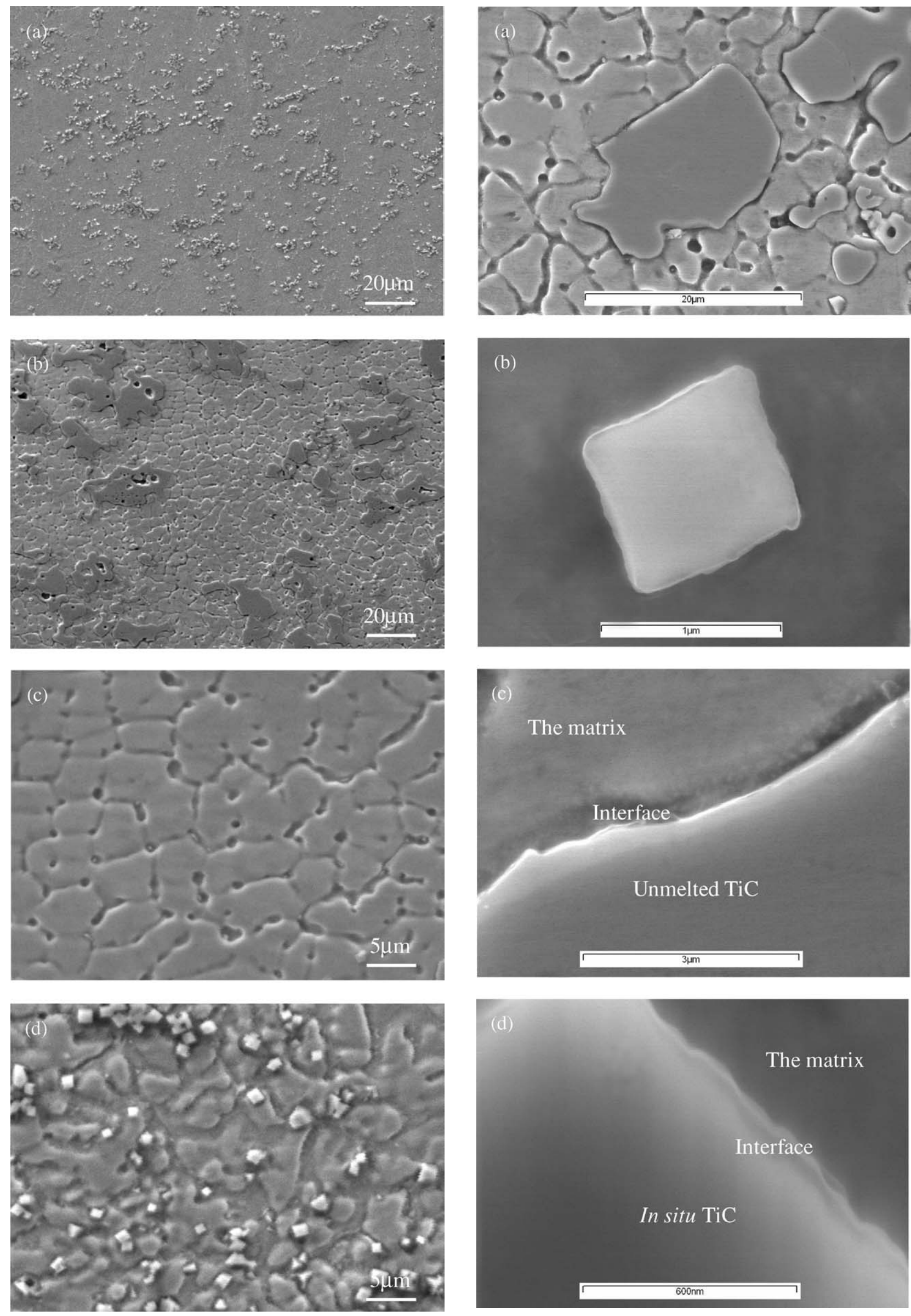

Figure 3 Microstructure of laser deposited particulate reinforced intermetallic matrix composite material: (a) In situ $\mathrm{TiC}$ particles dispersed on the matrix, (b) unmelted TiC particles and the matrix, (c) dense and homogenous intermetallic matrix and (d) fine in situ $\mathrm{TiC}$ particulates and the matrix.

Figure 4 A comparison of in situ and unmelted TiC particles and their interfaces with the matrix: (a) unmelted $\mathrm{TiC}$ paticle, (b) in situ TiC particles, (c) interface between unmelted TiC particle and the matrix and (d) interface between in situ TiC particle and the matrix. 


\section{Acknowledgments}

This research is funded by Postdoctoral Science Foundation of China and Prior Defensive Research Foundation of High Energy Beam Processing Technology of China. The authors thank Zhang Hongjun of Laser Processing Research Center of Tsinghua University for the laser processing experiment. They also thank Yang Wenyan of the National Key Laboratory for Tribology of China for the SEM analysis, and Yan Yunjie of the Advanced Materials Key Laboratory of Education Ministry of China, for the HSEM analysis.

\section{References}

1. C. T. LIU, J. STRINGER, J. N. MUNDY, L. L. HORTON and P. ANGELINI, Intermetallics 5 (1997) 579.
2. N. S. STOLOFF, C. T. LIU and S. C. DEEVI, ibid. $8(2000)$ 1313.

3. R. D. NOEBE, R. R. BOWMAN and M. V. NATHAL, Inter. Mater. Rev. 4 (1993) 193.

4. R. DAR OLIA, Intermetallics 8 (2000) 1321.

5. A. MISRA and R. GIBALA, ibid. 8 (2000) 1025.

6. A. MISRA, R. CIBALA and R. D. NOEBE, ibid. 9 (2001) 971.

7. L. M. PIKE, Y. A. CHANG and C. T. LIU, ibid. 5 (1997) 601.

8. C. M. WARD-CLOSE, R. MINOR and P. J. DOORBAR, ibid. 4 (1996) 217.

9. C. C. KOCH, Mater. Sci. Engng. A 224 (1998) 39.

10. Y. CHEN and H. M. WANG, Mater. Letter. 57 (2003) 2029.

11. S. GUB A, I. B A KER and P. R. MUNROR, Mater. Sci. Engng. A 131 (1991) 27.

Received 5 January

and accepted 3 February 2004 